\title{
Genetic separation of southern and northern soybean breeding programs in North America and their associated allelic variation at four maturity loci
}

\author{
Goettel Wolfgang • Yong-qiang Charles An, PhD
}

Received: 29 September 2015 / Accepted: 21 December 2016 / Published online: 11 January 2017

(C) The Author(s) 2017. This article is published with open access at Springerlink.com

\begin{abstract}
North American soybean breeders have successfully developed a large number of elite cultivars with diverse maturity groups (MG) from a small number of ancestral landraces. To understand molecular and genetic basis underlying the large variation in their maturity and flowering times, we integrated pedigree and maturity data of 166 cultivars representing North American soybean breeding. Network analysis and visualization of their pedigree relationships revealed a clear separation of southern and northern soybean breeding programs, suggesting that little genetic exchange occurred between northern (MG 0-IV) and southern cultivars (MG VVIII). We also analyzed the transcript sequence and expression levels of four major maturity genes (E1 to E4) and revealed their allelic variants in 75 major ancestral landraces and milestone cultivars. We observed that $e 1$-as was the predominant $e$ mutant allele in northern genotypes, followed by $e 2$ and $e 3$. There was no allelic variation at E4. Transcript accumulation of the $e 2$ mutant allele was significantly reduced, which might be caused by its premature stop codon triggering the nonsensemediated mRNA decay pathway. The large DNA deletion generating the e3 mutant allele also created a gene
\end{abstract}

Electronic supplementary material The online version of this article (doi:10.1007/s11032-016-0611-7) contains supplementary material, which is available to authorized users.

G. Wolfgang • Y.-q. C. An PhD ( $\bowtie)$

US Department of Agriculture, Agricultural Research Service, Midwest Area, Plant Genetics Research Unit at Donald Danforth Plant Science Center, 975 N Warson Rd, St. Louis, MO 63132, USA

e-mail: yong-qiang.an@ars.usda.gov fusion transcript. The $e$ alleles found in milestone cultivars were traced through pedigrees to their ancestral landraces and geographic origins. Our analysis revealed an approximate correlation between dysfunctional alleles and maturity groups for most of the 75 cultivars. However, single $e$ mutant alleles and their combinations were not sufficient to fully explain their maturity diversity, suggesting that additional genes/alleles are likely involved in regulating maturity time.

Keywords Soybean · breeding history · Pedigree . Breeding $\cdot$ Network . $E$ genes and maturity

Soybean (Glycine $\max (\mathrm{L}$.$) Merrill) is a photoperiod-$ sensitive plant that flowers in response to shorter day length. Soybean cultivars have to acquire photoperiodic insensitivity to flower and produce seeds at higher latitudes (Xu et al. 2013). Soybean was domesticated from its wild relative Glycine soja in East Asia several thousand years ago. In contrast, soybean has a rather short history in North America. Soybean was only introduced to North America in the seventeenth century and was mostly grown as a forage crop until the 1920s. The first modern soybean cultivar developed by hybridization in North American breeding programs was released in 1939 (Bernard et al. 1988). The transition from selecting landraces to breeding cultivars resulted in a significant genetic improvement of soybean cultivars (Rincker et al. 2014). 
During soybean domestication and breeding, soybean cultivars with a wide range of flowering and maturity time were developed. Current soybean cultivars have been bred to grow in latitudes ranging from the equator to $50^{\circ} \mathrm{N}$ and higher (Tsubokura et al. 2013). In general, a given cultivar is developed for maximum yield potential within a specific latitude range. Cultivars are assigned to specific maturity groups ranging from 000 to $\mathrm{X}$, which indicate their preferred latitudinal or geographic zones in North America from Southern Canada (000) to Mexico and the Caribbean Islands (X).

Cultivars with a wide range of maturity groups have been bred in North America since the first soybean hybrid cultivar was released. To associate soybean maturity with North American soybean pedigrees, we compiled pedigree and maturity group data of 166 soybean genotypes through comprehensive database and literature searches. These genotypes include landrace and milestone cultivars that represent 90 years of North American soybean breeding. The cultivars belong to diverse maturity groups (MG) from 0 to VIII. The pedigree data were analyzed and visualized using a networking approach (Shannon et al. 2003) (Fig. 1). A total of 166 soybean cultivars were represented as nodes and 274 parent-offspring relationships were represented as directed edges pointing from parental to progeny cultivars. The soybean cultivars grouped into two distinct clusters (Fig. 1). The smaller cluster contained 55 cultivars and 85 parent-offspring connections, and the larger cluster consisted of $110 \mathrm{cul}-$ tivars with 180 parent-offspring relations. Only eight parent-offspring relations bridged the two clusters. Interestingly, the two clusters were defined by cultivars of either northern (MG 0-IV) or southern (MG V to VIII) maturity groups. Cultivars in the smaller cluster exclusively belonged to maturity groups $0-\mathrm{IV}$, while cultivars in the larger cluster predominantly belonged to maturity groups V-VIII. Only five of the 110 cultivars in the large southern cluster were northern cultivars. For example, Perry, a milestone cultivar in maturity group IV, was situated in the southern cluster. A small number of landrace and milestone cultivars had offspring in both clusters and thereby bridged them. Those cultivars were situated closer to the border between both clusters. For instance, Illini/A.K. (Harrow) (MG III) gave rise to Adams (MG III) in the northern cluster and S-100 (MG V) in the southern cluster, and Dunfield produced Adams in the northern cluster and Dorman in the southern cluster. The pedigree network analysis clearly demonstrated the separation of northern and southern breeding programs. This separation presumably limited genetic exchange between northern and southern cultivars and may have created distinct gene pools for southern and northern breeding programs respectively. Beneficial alleles, which are uniquely selected in southern or northern breeding program, could be integrated together by crossing southern and northern genotypes.

To understand genetic and molecular basis underlying maturity and flowering time variations of major cultivars, we selected 75 of the 166 genotypes for further analysis. The 75 genotypes represent historically and economically important landrace and milestone cultivars (Table 1). Forty cultivars have maturity groups (MG) 0 to IV, while 35 cultivars are assigned to maturity groups V to VIII. The landraces were collected in East Asia from a wide range of latitudes. They comprise 14 landraces from China, three from North Korea, one from Japan, and one from an unknown origin. Overall, landraces were preferentially introduced from Asia to locations of similar latitude in North America and were subsequently used to develop a variety of cultivars at these sites (Fig. 2). For about $70 \%$ of the landraces, the latitudes of collection and introduction sites differed by less than $3.7^{\circ}$. For example, Mandarin (Ottawa) originated in Heilongjiang, China and was introduced in Ontario, Canada. Likewise, Mukden was brought from Liaoning, China to Iowa, USA.

The divergence in flowering time and maturity between southern and northern genotypes likely represents one of the major factors leading to the two genetically separated breeding populations. Although more than 100 genes may be involved in flowering pathways in soybean (Kim et al. 2012), only ten loci (E1-E9, J) have been mapped and reported to control time to flowering and maturity. Maturity genes E1,E2, E3, and E4 have been identified and sequenced (Liu et al. 2008; Tsubokura et al. 2013; Watanabe et al. 2012; Watanabe et al. 2009; Watanabe et al. 2011; Xia et al. 2012), and various soybean cultivars have been screened for their allelic variants (Langewisch et al. 2014; Tsubokura et al. 2014; Zhai et al. 2014). It has been estimated that the four maturity genes contribute between 62 and $66 \%$ of variation of flowering time in a population containing 63 soybean accessions (Tsubokura et al. 2014). We recently sequenced soybean seed transcriptomes of the 75 landraces and milestone cultivars at a seed mid-maturation stage, which provided us the opportunity to investigate molecular and genetic changes of the four maturity genes simultaneously in those cultivars. We determined the transcript sequence and expression levels of the E1 to 


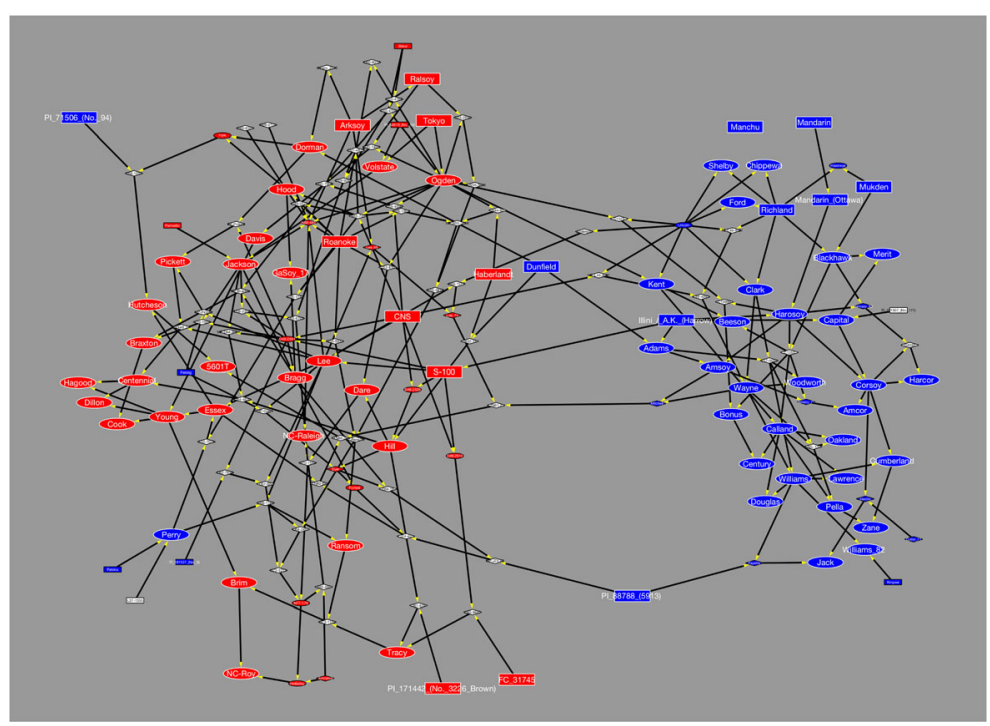

Fig. 1 Separation of southern and northern genotypes. Pedigree data for all genotypes are shown as a directional network, in which soybean genotypes are represented as nodes and their relationship as edges. Edge points from parental lines to progeny lines as indicated by the yellow arrowheads. Landraces, milestone cultivars, and intermediate breeding lines are shown as rectangles, ellipses, and diamonds, respectively. Nodes shown in blue

E4 genes and/or associated the allelic variants with the maturity ratings of their soybean cultivars.

Maturity gene E2 E2 has high homology to the Arabidopsis GIGANTEA protein, which is involved in the circadian clock of the flowering time pathway (Watanabe et al. 2011). E2 presumably controls the expression of the Flowering Locus T (FT) orthologs, which encode florigens (i.e., leaf-derived, mobile, long-distance signals promoting floral transition) (Watanabe et al. 2011). A nonsynonymous SNP in an $e 2$ allele has recently been reported where a thymine (T) was substituted for an adenine (A) resulting in a nonsense mutation (Watanabe et al. 2011). This premature stop codon truncates the E2 protein from 1170 amino acids to 521 amino acids, which lead to early flowering. We observed that E2 (Glyma.10G221500) was highly expressed in seeds (Suppl. Fig. 1A). E2 contained four SNPs in those genotypes, i.e., one synonymous SNP (chr10: $45,305,867$ ), two nonsynonymous SNPs (chr10: 45,305,285, chr10: 45,310,798), and one SNP in the 3' UTR (chr10: 45,315,921) (Suppl. Fig. 1A). The nonsynonymous SNP at chr10: 45,310,798 resulted in the previously reported premature stop represent soybean lines belonging to maturity groups $0-\mathrm{IV}$, while nodes in red indicate lines with maturity ratings V-VIII. Genotypes whose maturity data were not available are shown as white nodes. Genotypes associated with large nodes surrounded by white borders were sequenced. The network analysis reveals two main clusters containing soybean lines adapted to more northern or southern growing zones (color figure online)

codon and the production of the truncated nonfunctional E2 protein (Watanabe et al. 2011). This SNP was detected in 17 of the 75 examined cultivars (Table 2 and Suppl. Fig. 1A). With the exception of PI 171442, all cultivars carrying this nonsense mutation belonged to the northern maturity groups 0 to IV. Thus, this SNP represented an important functional allele accounting for some of the maturity variations in the landrace and milestone cultivars. However, none of the other three SNPs showed any significant correlation with maturity groups. Interestingly, we observed a lower expression of the $e 2$ mutant allele compared to the functional E2 alleles. The average $e 2$ transcript accumulation was reduced to a level of 9.71 FPKM (Fragments Per Kilobase of transcript per Million mapped reads) from an average E2 level of 21.99 FPKM. The decreased $e 2$ transcript accumulation might be caused by the premature stop codon through the nonsense-mediated mRNA decay (NMD) pathway (Merai et al. 2013).

We determined the haplotype block structure containing the E2 gene using the Haploview software package (Barrett et al. 2005). We identified three major haplotypes and one minor haplotype where 
Table 1 List of landraces and milestone cultivars and their allelic variants at maturity genes $E 1$ to $E 4$

\begin{tabular}{|c|c|c|c|c|c|c|c|}
\hline Name $^{a}$ & Accession & Cultivar & Maturity group & E1 & $E 2$ & $E 3$ & $E 4$ \\
\hline Capital & PI 548311 & Milestone & 0 & $e 1-a s$ & $E 2$ & $e 3$ & E4 \\
\hline Mandarin (Ottawa) & PI 548379 & Landrace & 0 & el-as & $\mathrm{e} 2$ & $e 3$ & E4 \\
\hline Merit & PI 548545 & Milestone & 0 & E1 & $\mathrm{e} 2$ & $e 3$ & E4 \\
\hline Blackhawk & PI 548516 & Milestone & I & E1 & $\mathrm{e} 2$ & $e 3$ & E4 \\
\hline Chippewa & PI 548530 & Milestone & I & el-as & $\mathrm{e} 2$ & $e 3$ & E4 \\
\hline Mandarin & PI 548378 & Landrace & I & el-as & $\mathrm{e} 2$ & E3 & E4 \\
\hline Amcor & PI 548505 & Milestone & II & el-as & $E 2$ & $e 3$ & E4 \\
\hline Amsoy & PI 548506 & Milestone & II & el-as & $\mathrm{e} 2$ & E3 & E4 \\
\hline Beeson & PI 548510 & Milestone & II & E1 & $\mathrm{e} 2$ & $E 3$ & E4 \\
\hline Century & PI 548512 & Milestone & II & el-as & $\mathrm{e} 2$ & E3 & E4 \\
\hline Corsoy & PI 548540 & Milestone & II & el-as & $E 2$ & $e 3$ & E4 \\
\hline Harcor & PI 548570 & Milestone & II & el-as & $E 2$ & $e 3$ & E4 \\
\hline Harosoy & PI 548573 & Milestone & II & el-as & $\mathrm{e} 2$ & $E 3$ & E4 \\
\hline Jack & PI 540556 & N/A & II & el-as & $E 2$ & E3 & E4 \\
\hline Mukden & PI 548391 & Landrace & II & E1 & $\mathrm{e} 2$ & E3 & E4 \\
\hline Richland & PI 548406 & Landrace & II & E1 & $\mathrm{e} 2$ & $e 3$ & E4 \\
\hline 5913 & PI 88788 & Landrace & III & E1 & $E 2$ & E3 & E4 \\
\hline A.K. (Harrow) & PI 548298 & Landrace & III & E1 & $E 2$ & E3 & E4 \\
\hline Adams & PI 548502 & Milestone & III & E1 & $\mathrm{e} 2$ & E3 & E4 \\
\hline Calland & PI 548527 & Milestone & III & el-as & $\mathrm{e} 2$ & E3 & E4 \\
\hline Cumberland & PI 548542 & Milestone & III & el-as & $E 2$ & E3 & E4 \\
\hline Dunfield & PI 548318 & Landrace & III & E1 & $\mathrm{e} 2$ & E3 & E4 \\
\hline Ford & PI 548562 & Milestone & III & el-as & $E 2$ & E3 & E4 \\
\hline Illini & PI 548348 & Landrace & III & E1 & $E 2$ & E3 & E4 \\
\hline Manchu & PI 548365 & Landrace & III & el-as & $E 2$ & $E 3$ & E4 \\
\hline Oakland & PI 548543 & Milestone & III & $e 1-a s$ & $E 2$ & E3 & E4 \\
\hline Pella & PI 548523 & Milestone & III & el-as & $\mathrm{e} 2$ & $E 3$ & E4 \\
\hline Shelby & PI 548574 & Milestone & III & el-as & $E 2$ & E3 & E4 \\
\hline Wayne & PI 548628 & Milestone & III & el-as & $E 2$ & $E 3$ & E4 \\
\hline Williams & PI 548631 & Milestone & III & el-as & $E 2$ & E3 & E4 \\
\hline Williams 82 & PI 518671 & Milestone & III & el-as & $E 2$ & $E 3$ & E4 \\
\hline Woodworth & PI 548632 & Milestone & III & el-as & $E 2$ & E3 & E4 \\
\hline Zane & PI 548634 & Milestone & III & el-as & $E 2$ & E3 & E4 \\
\hline Bonus & PI 548517 & Milestone & IV & el-as & $E 2$ & $E 3$ & E4 \\
\hline Clark & PI 548533 & Milestone & IV & el-as & $E 2$ & E3 & E4 \\
\hline Douglas & PI 548555 & Milestone & IV & el-as & $E 2$ & $E 3$ & E4 \\
\hline Kent & PI 548586 & Milestone & IV & el-as & $E 2$ & $E 3$ & E4 \\
\hline Lawrence & PI 518673 & Milestone & IV & el-as & $E 2$ & $E 3$ & E4 \\
\hline No. 94 & PI 71506 & Landrace & IV & E1 & $\mathrm{e} 2$ & $e 3$ & E4 \\
\hline Perry & PI 548603 & Milestone & IV & E1 & $E 2$ & E3 & E4 \\
\hline $5601 \mathrm{~T}$ & PI 630984 & Milestone & $\mathrm{V}$ & E1 & $E 2$ & $E 3$ & E4 \\
\hline Dare & PI 548987 & Milestone & $\mathrm{V}$ & E1 & $E 2$ & E3 & E4 \\
\hline Dorman & PI 548653 & Milestone & $\mathrm{V}$ & E1 & $E 2$ & $e 3$ & E4 \\
\hline Essex & PI 548667 & Milestone & $\mathrm{V}$ & E1 & $E 2$ & E3 & $E 4$ \\
\hline
\end{tabular}


Table 1 (continued)

\begin{tabular}{|c|c|c|c|c|c|c|c|}
\hline $\mathrm{Name}^{\mathrm{a}}$ & Accession & Cultivar & Maturity group & E1 & E2 & E3 & E4 \\
\hline Hill & PI 548654 & Milestone & $\mathrm{V}$ & E1 & $E 2$ & E3 & E4 \\
\hline Hutcheson & PI 518664 & Milestone & $\mathrm{V}$ & E1 & E2 & E3 & E4 \\
\hline No. 3226 Brown & PI 171442 & Landrace & $\mathrm{V}$ & E1 & $\mathrm{e} 2$ & E3 & E4 \\
\hline S-100 & PI 548488 & Landrace & $\mathrm{V}$ & E1 & $E 2$ & E3 & E4 \\
\hline Arksoy & PI 548438 & Landrace & VI & E1 & E2 & $e 3$ & E4 \\
\hline Brim & PI 548986 & Milestone & VI & E1 & $E 2$ & E3 & E4 \\
\hline Centennial & PI 548975 & Milestone & VI & E1 & $E 2$ & E3 & E4 \\
\hline Davis & PI 553039 & Milestone & VI & E1 & $E 2$ & $E 3$ & $E 4$ \\
\hline Dillon & PI 592756 & Milestone & VI & E1 & E2 & E3 & E4 \\
\hline FC 31745 & FC 31745 & Landrace & VI & E1 & $E 2$ & E3 & E4 \\
\hline Haberlandt & PI 548456 & Landrace & VI & E1 & $E 2$ & $e 3$ & E4 \\
\hline Hood & PI 548980 & Milestone & VI & E1 & $E 2$ & E3 & E4 \\
\hline Lee & PI 548656 & Milestone & VI & E1 & $E 2$ & $E 3$ & E4 \\
\hline NC-Roy & PI 617045 & Milestone & VI & E1 & E2 & E3 & E4 \\
\hline Ogden & PI 548477 & Milestone & VI & E1 & $E 2$ & E3 & E4 \\
\hline Pickett & PI 548988 & Milestone & VI & E1 & E2 & E3 & E4 \\
\hline Ralsoy & PI 548484 & Landrace & VI & E1 & $E 2$ & $e 3$ & E4 \\
\hline Tracy & PI 548983 & Milestone & VI & E1 & $E 2$ & $E 3$ & $E 4$ \\
\hline Young & PI 508266 & Milestone & VI & E1 & $E 2$ & E3 & E4 \\
\hline Bragg & PI 548660 & Milestone & VII & E1 & $E 2$ & $E 3$ & E4 \\
\hline Braxton & PI 548659 & Milestone & VII & E1 & $E 2$ & E3 & E4 \\
\hline $\mathrm{CNS}$ & PI 548445 & Landrace & VII & E1 & E2 & E3 & E4 \\
\hline GaSoy 17 & PI 553046 & Milestone & VII & E1 & E2 & E3 & E4 \\
\hline Hagood & PI 555453 & Milestone & VII & E1 & E2 & E3 & E4 \\
\hline Jackson & PI 548657 & Milestone & VII & E1 & E2 & E3 & E4 \\
\hline NC-Raleigh & PI 641156 & Milestone & VII & E1 & $E 2$ & E3 & E4 \\
\hline Ransom & PI 548989 & Milestone & VII & E1 & $E 2$ & E3 & $E 4$ \\
\hline Roanoke & PI 548485 & Landrace & VII & E1 & $E 2$ & E3 & $E 4$ \\
\hline Tokyo & PI 548493 & Landrace & VII & E1 & E2 & E3 & E4 \\
\hline Volstate & PI 548494 & Milestone & VII & E1 & $E 2$ & E3 & E4 \\
\hline Cook & PI 553045 & Milestone & VIII & E1 & $E 2$ & E3 & $E 4$ \\
\hline
\end{tabular}

${ }^{\mathrm{a}}$ Cultivars are sorted by maturity group

N/A not available

E2 was embedded in (Suppl. Fig. 1A, B). Haplotype 1 contained the $e 2$ mutant allele with the premature stop codon, while none of haplotypes 2,3 , and 4 did. Interestingly, haplotypes 1 and 3 were identical with the exception of the nonsense mutation. The seventeen cultivars carrying haplotype 1 included seven landraces (Mandarin (I), Mandarin (Ottawa) (0), Mukden (II), Richland (II), Dunfield (III), PI 71506 (IV), and PI 171442 (V)) collected from various regions in China, and ten milestone cultivars derived from those landraces (Adams (III), Blackhawk (I), Chippewa (I), Harosoy (II), Merit (0), Amsoy (II), Calland (III), Beeson (II), Century (II), and Pella (III)). Thus, the nonsense SNP allele in haplotype 1 has been widely present in ancestral landraces. It likely arose as a single nucleotide mutation in a common progenitor genotype carrying haplotype 3 (Table 1 and Suppl. Fig. 1A). 

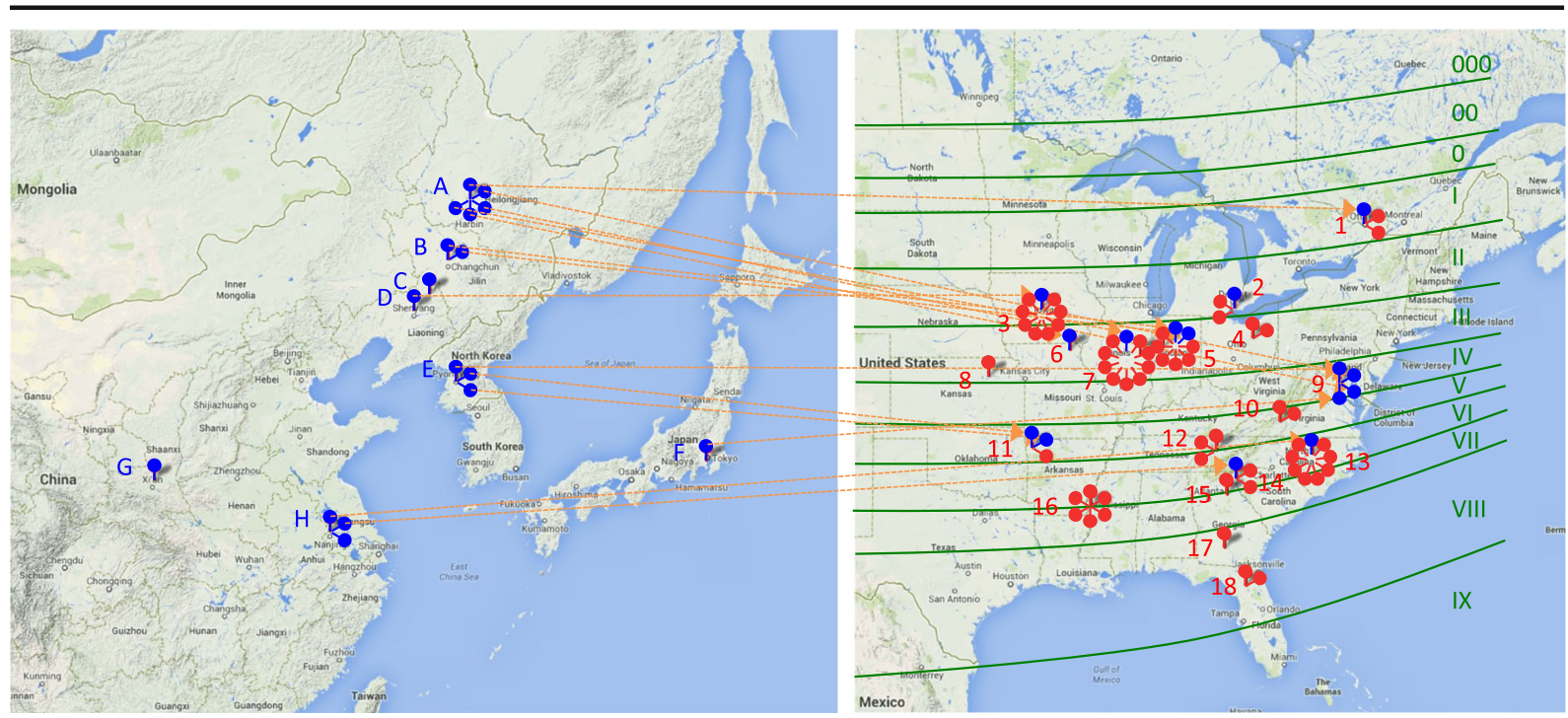

Fig. 2 Geographic locations of origin and development of landraces and milestone cultivars. The geographic maps of East Asia and North America are in scale and aligned by latitude. Soybean maturity zones ranging from 000 to $I X$ are superimposed on the map. Letters refer to locations of landrace collection in East Asia, and numbers indicate sites of landrace and/or milestone cultivar development in North America. Both are sorted by latitude from north to south. For few selected soybean varieties, dashed lines are shown connecting locations of origin with sites of introduction. Blue dots refer to landraces and red dots to milestone cultivars. Landraces (listed with maturity groups) were collected at following East Asian locations (country, province/city): A China, Heilongiiang: Illini (III), Manchu (III), Mandarin (Ottawa) (O), Mandarin (1), S-100 (V); B China, Jilin: Dunfield (III), Richland (II); $C$ China, Liaoning: PI 88788 (III); $D$ China, Liaoning: Mukden (II); $E$ North Korea, Pyongyang: Arksoy $(V I)$, Haberlandt (VI), Ralsoy $(V I)$; $F$ Japan, Kanagawa: Tokyo (VII); $G$ China, Shaanxi: PI 171442 (V); H China, Jiangsu: CNS (VII), PI 71506 (IV), Roanoke (VII). Landraces and milestone cultivars (listed with maturity groups) were developed at following sites in North America (country, state/province, city): 1 Canada, Ontario, Ottawa: Merit $(0)$, Capital (0), Mandarin (Ottawa) (0); 2 Canada, Ontario, Harrow: Harcor (II), Harosoy (II), A.K. (Harrow) (III); 3 USA, Iowa,

Maturity gene E3 The E3 gene (Glyma.19G224200) encodes a phytochrome A photoreceptor that affects the photoperiodic control of FT2 $a$ and FT5 $a$ expression and

Table 2 Summary of cultivars containing either $e 1, e 2$, or $e 3$ mutant allele

\begin{tabular}{llll}
\hline Gene & $\begin{array}{l}\text { No. of northern } \\
\text { cultivars MG 0-IV }\end{array}$ & $\begin{array}{l}\text { No. of southern cultivars } \\
\text { MG V-VIII }\end{array}$ & Total \\
\hline e1 & $28 / 40$ & $0 / 35$ & $28 / 75$ \\
$e 2$ & $16 / 40$ & $1 / 35$ & $17 / 75$ \\
$e 3$ & $10 / 40$ & $4 / 35$ & $14 / 75$ \\
\hline
\end{tabular}

Ames: Adams (III), Amsoy (II), Blackhawk (I), Corsoy (II), Cumberland (III), Ford (III), Oakland (III), Pella (III), Mukden (II); 4 USA, Ohio, Wooster: Amcor (II), Zane (III); 5 USA, Indiana, West Lafayette: Beeson (II), Bonus (IV), Calland (III), Century (II), Kent (IV), Perry (IV), Dunfield (III), Richland (II); 6 USA, Missouri, Rutledge: S-100 (V); 7 USA, Illinois, Urbana: Chippewa (I), Clark (IV), Jack (II), Lawrence (IV), Shelby (III), Wayne (III), Williams (III), Williams 82 (III), Woodworth (III), Illini (III); 8 USA, Kansas, Manhattan: Douglas (IV); 9 USA, Virginia, Arlington: Haberlandt (VI), Manchu (III); 10 USA, Virginia, Blacksburg: Essex (V), Hutcheson (V), Mandarin (I), Tokyo (VII); 11 USA, Arkansas, Fayetteville: Davis (VI), Arksoy (VI), Ralsoy (VI); 12 USA, Tennessee, Knoxville: 5601T (V), Ogden (VI), Volstate (VII); 13 USA, North Carolina, Raleigh: NC-Roy (VI), Brim $(V I)$, Dare $(V)$, Jackson (VII), NC-Raleigh (VII), Pickett (VI), Ransom (VII), Young (VI), Roanoke (VII); 14 USA, South Carolina, Clemson: Dillon (VI), Hagood (VII), CNS (VII); 15 USA, Georgia, Athens: Cook (VIII); 16 USA, Mississippi, Stoneville: Centennial $(V I)$, Dorman $(V)$, Hill $(V)$, Hood $(V I)$, Lee $(V I)$, Tracy $(V I)$; 17 USA, Georgia, Tifton: GaSoy17 (VII); 18 USA, Florida, Gainesville: Bragg (VII), Braxton (VII) (color figure online)

therefore flowering. Recently, a 13.3-kb deletion in an e3 allele has been detected, which starts in intron 4 and includes the entire $3^{\prime}$ end of the gene (Watanabe et al. 2009). The deletion of the histidine kinase domain renders the E3 protein nonfunctional, which results in an early flowering phenotype. A nonfunctional $e 3$ allele containing a 2.6-kb transposon insertion in intron 4 and a nonsynonymous SNP (G1050R) in exon 3 has been described as well (Shin and Lee 2012; Watanabe et al. 2009). We observed that the E3 gene is only weakly expressed in soybean seeds at a mean level of 0.93 FPKM with little variation in the examined cultivars. In addition, E3 had no SNPs in the regions sequenced in all cultivars. 
However, inspection of the short sequencing read alignments to the genomic reference sequence using the Integrative Genomics Viewer (IGV) revealed a large deletion in 14 of 75 soybean cultivars (Suppl. Fig. 2A) (Robinson et al. 2011; Thorvaldsdóttir et al. 2013). The deletion is likely identical with the $13.3-\mathrm{kb}$ deletion previously reported in the $E 3$ gene that results in an early flowering phenotype (Watanabe et al. 2009). The deletion also starts in intron 4 and probably includes the adjacent gene model Glyma.19G224300, which is not expressed in e3 mutants and about $7.3 \mathrm{~kb}$ apart from exon 4 of $e 3$ (Suppl. Fig. 2A). Interestingly, a number of sequencing reads contained the splice junction of exon 4 from $e 3$ (G1yma.19G224200) and exon 2 from Glyma.19G224400, which are $18 \mathrm{~kb}$ apart in the Williams 82 reference genome, suggesting that transcription cross the deletion junction into Glyma.19G224400, followed by splicing of the novel intron. Therefore, the deletion generated a chimeric transcript consisting of the truncated e3 allele and Glyma.19G224400. The e3 deletion was present in six landraces (Arksoy (VI), Ralsoy (VI), Haberlandt (VI), Mandarin (Ottawa) (0), PI 71506 (IV), and Richland (II)) and eight milestone lines (Capital (0), Blackhawk (I), Chippewa (I), Dorman (V), Merit (0), Amcor (II), Corsoy (II), and Harcor (II)) (Table 1 and Suppl. Fig. 2A). They belong to maturity groups ranging from 0 to VI. The $e 3$ mutant landraces were collected in various regions in China and North Korea, which indicate the wide distribution of the $e 3$ mutant allele. In addition, we identified six haplotypes containing the $E 3$ gene, which spanned about $213 \mathrm{~kb}$ (Suppl. Fig. 2B, C). The e3 deletion allele was located in haplotype 1 . The predominant haplotype 6 was found in cultivars with maturity groups from I to VIII, while haplotype 3 was associated with southern maturity groups V to VII. The remaining haplotypes 2, 4, and 5 are rare, as none of them were present in more than three cultivars (Suppl. Fig. 2B).

Maturity gene E4 Similar to E3, E4 (Glyma.20G090000) also encodes a phytochrome A (phyA) photoreceptor, which controls the Flowering Locus T orthologs FT2a and FT5a (Liu et al. 2008; Tsubokura et al. 2013). Five nonfunctional alleles have been reported. They are caused by one 6.2-kb retroelement insertion in exon 1 ( $e 4$ (SORE1)) and four 1-bp deletions (e4-oto, e4-tsu, e4-kam, e4kes) in the coding region creating frameshifts, premature stop codons, and truncated proteins (Liu et al. 2008; Tsubokura et al. 2013). E4 was expressed in midmaturation seeds at mean FPKM levels of 3.21. Although various $e 4$ mutant alleles have been identified previously, we did not detect any SNPs, small indels, or significant expression variation among our 75 cultivars. Neither did we find larger deletions or insertion upon visual inspection of sequencing read alignments, suggesting that there is no obvious genetic variation of $E 4$ among the 75 genotypes. Consequently, E4 does not seem to contribute to the maturity variation of those landrace and milestone cultivars. $E 4$ cannot be assigned to a haplotype block either.

Maturity gene E1 E1 encodes a putative transcription factor containing a plant-specific B3 domain. E1 inhibits the floral induction under long-day growth conditions as it suppresses the expression of the Flowering Locus $T$ orthologs FT2 $a$ and FT5a. The expression of E1 is under the photoperiodic control of E3 and E4 (Xu et al. 2015). Several nonfunctional $e 1$ alleles have been identified. $e 1-$ $f_{s}$ allele has a 1-bp deletion causing a frameshift, and $e 1$ $n l$ is a null allele with a deletion of the entire $E l$ gene. A missense point mutation at nucleotide 44 in the nuclear localization signal of the e1-as allele results in a dysfunctional protein and early flowering (Xia et al. 2012). In contrast to $E 2, E 3$, and $E 4$, we did not detect any expression of E1 (Glyma.06G207800) in seeds. However, we identified a haplotype block that contained the $E 1$ gene in five distinct haplotypes among the examined cultivars (Suppl. Fig. 3). Williams 82 carries the recessive e1-as mutant allele (Xia et al. 2012). Twenty-seven cultivars revealed the same haplotype 1 as Williams 82 (Table 1 and Suppl. Fig. 3), suggesting that they may carry the same el-as allele. Three landraces (Mandarin, Mandarin (Ottawa), and Manchu) were among the 27 cultivars. Interestingly, all landraces that gave rise to the putative

Table 3 Summary of cultivars containing $e 1$, e2, or $e 3$ single, double, or triple mutant alleles

\begin{tabular}{llllll}
\hline E1 & E2 & E3 & $\begin{array}{l}\text { No. of northern } \\
\text { cultivars MG } \\
\text { 0-IV }\end{array}$ & $\begin{array}{l}\text { No. of southern } \\
\text { cultivars MG } \\
\text { V-VIII }\end{array}$ & MG range \\
\hline e1-as & $\mathrm{e} 2$ & $e 3$ & 2 & 0 & $0-\mathrm{I}$ \\
$e 1-a s$ & $\mathrm{e} 2$ & $E 3$ & 6 & 0 & I-III \\
e1-as & $E 2$ & $E 3$ & 16 & 0 & II-IV \\
e1-as & $E 2$ & $e 3$ & 4 & 0 & $0-\mathrm{II}$ \\
$E 1$ & $\mathrm{e} 2$ & $e 3$ & 4 & 0 & $0-\mathrm{IV}$ \\
$E 1$ & $\mathrm{e} 2$ & $E 3$ & 4 & 1 & II-V \\
$E 1$ & $E 2$ & $e 3$ & 0 & 4 & V-VI \\
$E 1$ & $E 2$ & $E 3$ & 4 & 30 & III-VIII \\
\hline
\end{tabular}


25 e1-as milestone cultivars were collected in Heilongjiang, a region in Northeast China (Fig. 2), indicating that the $e 1$-as allele may have originated in Heilongiiang. The 28 presumably e1-as cultivars belonged to maturity groups 0 to IV, which accounted for $70 \%$ of the examined 40 northern cultivars (Suppl. Fig. 3 and Table 2).

The $e 1$-as allele represented the most predominant $e$ mutant allele among our examined North American cultivars, followed by $e 2$ and then $e 3$ (Table 2). E4 unlikely contributed to the maturity variations of the landrace and milestone cultivars. The el-as haplotype was only detected in northern cultivars and not in any southern cultivar. However, one $e 2$ allele and four $e 3$ alleles have been identified within southern genotypes (Table 2). Our results support the previous hypthesis that $E 1$ has the strongest and $E 3$ the weakest effect on flowering time among the E1,E2, and E3 genes (Tsubokura et al. 2014). However, those mutant alleles likely have additive and combinatorial effects. Double mutant cultivars with e1/e2 (MG I to III), e1/e3 (MG 0 to II), and e2/e3 (MG 0 to IV) alleles exclusively belong to northern maturity groups (Table 3). Triple mutant cultivars, i.e., Mandarin (Ottawa) and Chippewa, are in maturity groups 0 and I, respectively. Interestingly, cultivars containing the same allelic combinations could differ dramatically in their maturity rating. The allelic variations and their combinations did not entirely correlate with maturity ratings of the landrace and milestone cultivars. In addition, none of four northern genotypes PI 88788, Illini, A.K. (Harrow), and Perry contained any of the $e 1, e 2$, or $e 3$ mutant alleles (Table 1 and Table 3). Thus, it is likely that allelic variations at additional maturity loci are present in those landrace and milestone cultivars. Our observation is consistent with an earlier study of different soybean cultivars, in which only 62 to $66 \%$ of variation of flowering time could be explained by the E1 to E4 maturity genes (Tsubokura et al. 2014).

Acknowledgements The authors would like to thank Rick Meyer for his technical support in computational data processing and analysis and Drs. Jim Specht and Randy Shoemaker for sharing information about cultivars and providing seeds. This research is supported by funds from the United Soybean Board and USDAARS to Yong-qiang Charles An.

\section{Compliance with ethical standards}

Disclaimer note Names are necessary to report factually on available data; however, the USDA neither guarantees nor warrants the standard of the product, and the use of the name by
USDA implies no approval of the product to the exclusion of others that may also be suitable. USDA is an equal opportunity provider and employer.

Open Access This article is distributed under the terms of the Creative Commons Attribution 4.0 International License (http:// creativecommons.org/licenses/by/4.0/), which permits unrestricted use, distribution, and reproduction in any medium, provided you give appropriate credit to the original author(s) and the source, provide a link to the Creative Commons license, and indicate if changes were made.

\section{References}

Barrett JC, Fry B, Maller J, Daly MJ (2005) Haploview: analysis and visualization of LD and haplotype maps. Bioinformatics 21:263-265. doi:10.1093/bioinformatics/bth457

Bernard LR, Juvik GA, Hartwig EE, Edwards CJ (1988) Origins and pedigrees of public soybean varieties in the United States and Canada. United States Department of AgricultureAgricultural Research Service-Technical Bulletin 1746:172

Kim MY, Shin JH, Kang YJ, Shim SR, Lee S-H (2012) Divergence of flowering genes in soybean. J Biosci 37 : 857-870

Langewisch T, Zhang H, Vincent R, Joshi T, Xu D, Bilyeu K (2014) Major soybean maturity gene haplotypes revealed by SNPViz analysis of 72 sequenced soybean genomes. PLoS One 9:e94150. doi:10.1371/journal.pone.0094150

Liu B, Kanazawa A, Matsumura H, Takahashi R, Harada K, Abe J (2008) Genetic redundancy in soybean photoresponses associated with duplication of the phytochrome A gene. Genetics 180:995-1007. doi:10.1534/genetics.108.092742

Merai Z et al (2013) The late steps of plant nonsense-mediated mRNA decay. Plant J 73:50-62. doi:10.1111/tpj.12015

Rincker K et al (2014) Genetic improvement of U.S. soybean in maturity groups II, III, and IV. Crop Sci 54:1-14

Robinson JT, Thorvaldsdóttir H, Winckler W, Guttman M, Lander ES, Getz G, Mesirov JP (2011) Integrative genomics viewer. Nat Biotechnol 29:24-26. doi:10.1038/nbt.1754

Shannon P et al (2003) Cytoscape: a software environment for integrated models of biomolecular interaction networks. Genome Res 13:2498-2504. doi:10.1101/gr.1239303

Shin JH, Lee S-H (2012) Molecular markers for the E2 and E3 genes controlling flowering and maturity in soybean. Mol Breed 30:1793-1798. doi:10.1007/s11032-012-9743-6

Thorvaldsdóttir H, Robinson JT, Mesirov JP (2013) Integrative genomics viewer (IGV): high-performance genomics data visualization and exploration. Brief Bioinformatics 14:178192. doi:10.1093/bib/bbs017

Tsubokura Y et al (2013) Genetic variation in soybean at the maturity locus E4 is involved in adaptation to long days at high latitudes. Agronomy 3:117-134

Tsubokura Y et al (2014) Natural variation in the genes responsible for maturity loci E1, E2, E3 and E4 in soybean. Ann Bot 113: 429-441 
Watanabe S, Harada K, Abe J (2012) Genetic and molecular bases of photoperiod responses of flowering in soybean. Breed Sci 61:531-543. doi:10.1270/jsbbs.61.531

Watanabe $S$ et al (2009) Map-based cloning of the gene associated with the soybean maturity locus E3. Genetics 182:12511262. doi:10.1534/genetics. 108.098772

Watanabe $\mathrm{S}$ et al (2011) A map-based cloning strategy employing a residual heterozygous line reveals that the GIGANTEA gene is involved in soybean maturity and flowering. Genetics 188:395-407. doi:10.1534/genetics.110.125062

Xia Z et al (2012) Positional cloning and characterization reveal the molecular basis for soybean maturity locus E1 that regulates photoperiodic flowering. Proc Natl Acad Sci U S A 109: E2155-E2164. doi:10.1073/pnas.1117982109
Xu M et al (2013) Genetic variation in four maturity genes affects photoperiod insensitivity and PHYA-regulated postflowering responses of soybean. BMC Plant Biol 13:91. doi:10.1186/1471-2229-13-91

$\mathrm{Xu}$ M et al (2015) The soybean-specific maturity gene E1 family of floral repressors controls night-break responses through down-regulation of FLOWERING LOCUS T orthologs. Plant Physiol 168:1735-1746. doi:10.1104/pp.15.00763

Zhai $\mathrm{H}$ et al (2014) Allelic variations at four major maturity e genes and transcriptional abundance of the e1 gene are associated with flowering time and maturity of soybean cultivars. PLoS One 9:e97636. doi:10.1371/journal.pone.0097636 